\title{
Análise de óleos e graxas em efluentes por espectrofotometria
}

\begin{abstract}
Marina Kich ${ }^{1}$ e Wolmir José Böckel ${ }^{2}$
1 Graduada em Química Industrial pela Universidade do Vale do Taquari - Univates, Brasil. E-mail: marina.kich@gmail.com

2 Doutorado e Mestrado em Química pela Universidade Federal do Rio Grande do Sul, e graduado em Química Industrial pela Universidade de Santa Cruz do Sul e Química Licenciatura Plena pela Universidade de Santa Cruz do Sul. Professor Adjunto e Docente do Programa de Pós-Graduação em Ensino de Ciências Exatas na Universidade do Vale do Taquari - Univates, Brasil. E-mail: wjbockel@univates.br
\end{abstract}

RESUMO: A poluição ambiental é uma preocupação mundial, principalmente a poluição de corpos hídricos. Para medir o nível de poluição, a legislação ambiental utiliza parâmetros como indicadores da qualidade. Efluentes de postos de lavagens de carros e de oficinas mecânicas possuem alto poder poluidor devido a quantidade de óleo proveniente de peças e motores de automóveis. O método oficial para o Rio Grande do Sul, em conformidade com a Fundação Estadual de Proteção Ambiental Henrique Luiz Roessler (Fepam), é por gravimetria. Porém, é um método que demanda relativamente mais tempo e mais etapas do que em uma análise espectrofotométrica. Portanto, o presente estudo teve por objetivo o desenvolvimento de uma metodologia por espectrofotometria para análise de óleos e graxas. As amostras provenientes de oficinas mecânicas e postos de lavagem de carros foram coletadas por um laboratório credenciado pelo Ministério da Agricultura, Agropecuária e Abastecimento (MAPA) e Inmetro, de um município situado no Rio Grande do Sul. As amostras foram submetidas à análise pelo método oficial e comparou-se os resultados com o método proposto. Os resultados demonstraram que os testes de recuperação se situaram dentro da faixa aceita e demonstraram ser lineares. Dessa maneira, apresenta uma perspectiva positiva para ser utilizado como método alternativo com menor tempo de análise.

Palavras-chave: Poluição. Postos de lavagem. Oficina mecânica. Gravimetria.

\section{Analysis of oils and grease in wastewater by spectrophotometry}

ABSTRACT: Environmental pollution is a worldwide concern, especially pollution of water bodies. To measure the level of pollution, environmental legislation uses parameters as indicators of quality. Effluents from wash stations and mechanical workshops have a high polluting power due to the amount of oil coming from automobile parts and motors. Gravimetry is the official method for Rio Grande do Sul, according to the State Foundation for Environmental Protection Henrique Luiz Roessler (Fepam). However, a method requires relatively more time and more steps than in a spectrophotometric analysis. Therefore, the present study aimed to develop a spectrophotometric methodology for the analysis of oils and greases. The samples from mechanical workshops and washing stations were collected by a laboratory accredited by the Ministry of Agriculture, Farming and Supply (MAPA) and Metrology institute (Inmetro) from a city located in Rio Grande do Sul. The samples were submitted to analysis by the official method and the results were compared to the proposed method. The results showed that the recovery tests were within the accepted range and showed to be linear. In this way, it presents a positive perspective to be used as an alternative method with less analysis time.

Keywords: Pollution. Washing stations. Mechanical workshop. Gravimetry. 


\section{INTRODUÇÃO}

A poluição da água é uma alteração indesejável nas suas características químicas e físicas que venha causar prejuízos ao ser humano. O que determina a poluição é a quantidade de resíduo presente em determinado ambiente. Desta forma, para controlar a poluição, a legislação ambiental estabelece parâmetros e indicadores de qualidade que se deseja respeitar (BRAGA et al., 2005). Sendo, no Estado do Rio Grande do Sul, a Resolução vigente do Conselho Estadual do Meio Ambiente (CONSEMA) no 355/2017 (RIO GRANDE DO SUL, 2017).

Resíduos de óleos quando em contato com a água podem causar sérios danos ao meio ambiente, pois formam uma película impedindo a passagem de oxigênio para as células bacterianas e assim causando a morte de microrganismos (NUVOLARI, 2011). Efluentes de oficinas mecânicas e de postos de lavagem de veículos apresentam alto potencial poluidor, devido as suas características: efluentes com presença de óleo, sólidos sedimentáveis e detergentes. Sendo que as emulsões oleosas representam a mais expressiva forma de contaminação por óleo (INEA, 2014).

O método oficial para Laboratórios credenciados, conforme a Fundação Estadual de Proteção Ambiental Henrique Luiz Roessler (Fepam), para análise de óleos e graxas em efluentes de postos de lavagens e oficinas mecânicas é o método de gravimetria. (SMEWW, 2012). Porém, devido à demanda de maior tempo e maior número de etapas procedimentais para a análise gravimétrica, faz-se necessário a busca por metodologias alternativas que demandam menor tempo de análise. Devido a necessidade da determinação de baixas concentração de analitos e a rapidez requerida pela indústria, a análise química encontra-se extremamente dependente de equipamentos modernos que permitam a automação das análises (CIENFUEGOS, 2000).

Conforme Rocha e Teixeira (2004), a espectrofotometria é um método de baixo custo e grande número de aplicações. Porém não se tem conhecimento do seu uso na análise de óleos e graxas em efluentes desta natureza. O objetivo deste estudo foi a investigação da utilização da metodologia por Espectrofotometria na região de Ultravioleta - UV, na análise de óleos e graxas em efluentes e comparar seus resultados com o método da gravimetria que foi realizado por um laboratório credenciado.

\section{PARÂMETRO DE ÓLEOS E GRAXAS}

Óleos e graxas são substâncias orgânicas de origem animal, mineral ou vegetal. Geralmente são hidrocarbonetos, gorduras, ésteres, entre outros. Não costumam ser encontrados em águas naturais, mas provenientes de despejos e resíduos industriais, esgotos domésticos, efluentes de oficinas mecânicas, postos de gasolinas, estradas e vias públicas (ORSSATTO; HERMES; BOAS, 2010). Os óleos e graxas, em seu processo de decomposição, reduzem o oxigênio dissolvido elevando a Demanda Bioquímica de Oxigênio (DBO) e a Demanda Química de Oxigênio (DQO) causando alterações negativas no ecossistema aquático (METCALF \& EDDY. Inc., 1991).

Para o lançamento de efluentes em corpos hídricos o parâmetro de óleos e graxas é exigido pela legislação ambiental. Os limites de tolerância estão apresentados na Tabela 1 . 
Tabela 1: Limites legais de óleos e graxas para o lançamento de efluentes dados pela legislação Federal e Estadual.

Table 1: Legal limits of oils and greases for the discharge of effluents given by Federal and State legislation.

\begin{tabular}{lcc}
\hline Tipos de óleos e graxas & $\begin{array}{c}\text { Legislação } \\
\text { Federal }^{a}\end{array}$ & $\begin{array}{c}\text { Legislação } \\
\text { Estadual }^{b}\end{array}$ \\
\hline $\begin{array}{l}\text { Óleos e Graxas Minerais } \\
\text { Óleos e Graxas Vegetais e ou }\end{array}$ & $\leq 20 \mathrm{mg} \mathrm{L}^{-1}$ & $\leq 10 \mathrm{mg} \mathrm{L}^{-1}$ \\
Animais & $\leq 50 \mathrm{mg} \mathrm{L}^{-1}$ & $\leq 30 \mathrm{mg} \mathrm{L}^{-1}$ \\
\hline
\end{tabular}

Fonte: ${ }^{a}$ BRASIL (2005); ${ }^{b}$ RIO GRANDE DO SUL (2006).

A importância da determinação do teor de óleos e graxas deve-se ao fato que, quando concentrações elevadas estão presentes em águas residuárias, estas promovem problemas operacionais à etapa do tratamento primário, podendo interferir no tratamento biológico (secundário). Pode-se considerar que concentrações acima de 65 $\mathrm{mg} \mathrm{L}^{-1}$, de óleos e graxas, são suficientes para causar problemas operacionais ao sistema de tratamento hídrico (MELO, et al., 2002).

Para minimizar o problema de escoamento de óleos e graxas para as redes de esgoto público, a prefeitura municipal do município em que se realizou o estudo no Estado do Rio Grande do Sul, com base nas resoluções do CONAMA (BRASIL, 2011; BRASIL, 2005), exige para emissão da Licença de Operação que os estabelecimentos instalem uma caixa separadora de água e óleo, conforme mostra a Figura 1, onde ocorre a separação dos óleos e graxas do efluente que será lançado na rede pública, por meio de flotação natural. Para garantir que o sistema esteja funcionando de forma eficaz, o responsável pelo sistema emissor do efluente deve realizar limpezas nestas caixas, retirando a gordura que fica sedimentada no fundo e a destinando a empresas especializadas no descarte correto do resíduo, com uma periodicidade de 3 a 6 meses, dependendo do que está descrito na Licença de Operação do estabelecimento.
Dessa forma o município exige laudos de análises deste efluente, semestralmente, para a garantia que a limpeza está sendo realizada. Para determinar a periodicidade das análises e os parâmetros que deverão ser analisados, a Secretaria Municipal do Meio Ambiente baseia-se nas resoluções 355/2017 do CONSEMA, 430/2011 e 357/2005 do CONAMA (RIO GRANDE DO SUL, 2017; BRASIL, 2011; BRASIL, 2005).

Figura 1: Esquema de caixa separadora de água/óleo Figure 1: Water / Oil Separator Box Schematic

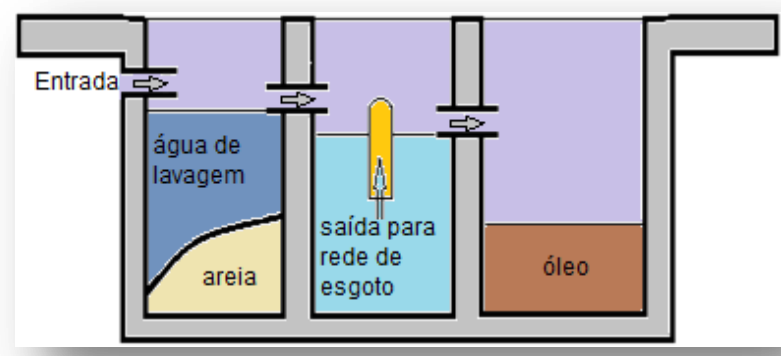

Fonte: Autores.

\section{COMPOSIÇÃO DE ÓLEOS LUBRIFICANTES}

Os primeiros óleos lubrificantes que surgiram no mercado foram os óleos de origem animal, porém com a modernização da indústria e por necessidade, atualmente, a base dos óleos lubrificantes passou a ser mineral, sintética e semissintética. Sendo, os mais utilizados, os de origem mineral, tem em sua composição uma mistura de hidrocarbonetos, provenientes do refino do petróleo. Os óleos lubrificantes possuem diversos tamanhos e formatos de moléculas com composição química em nitrogênio, enxofre e metais (AZEVEDO; CARVALHO; FONSECA, 2005). Devido à dificuldade do controle químico de materiais indesejáveis no processo, os óleos lubrificantes sintéticos estão sendo cada vez mais utilizados. Os 
óleos sintéticos não são derivados do petróleo, eles são produzidos em laboratórios. Já o óleo lubrificante mineral é um derivado do petróleo que representa em torno de $2 \%$ de todos os seus derivados, e normalmente não é totalmente consumido pelo motor dos automóveis durante o seu uso, assim podendo causar diversos problemas ambientais (AZEVEDO; CARVALHO; FONSECA, 2005).

Os óleos lubrificantes têm como seus componentes os aditivos, que após usados degradam-se, poluindo o meio ambiente. Um litro de óleo lubrificante de qualquer natureza polui um milhão de litros de água, equivalente a uma área superficial de 1000 $\mathrm{m}^{2}$ (SILVA et al., 2008; SILVEIRA et al., 2006).

\section{MÉTODOS DE ANÁLISE DE ÓLEOS E GRA- XAS}

O método da gravimetria é realizado pela extração dos óleos e graxas de uma amostra mediante a solubilização deste material em solvente apropriado. A amostra é acidificada e filtrada para que os óleos e graxas fiquem retidos no filtro. Este filtro então é seco em estufa e após extraído com solvente e em seguida o solvente é evaporado e o teor de óleos e graxas é obtido gravimetricamente, demandando um tempo de análise aproximado de cinco horas (SMEWW, 2012).

A espectrofotometria está fundamentada na lei de Lambert-Beer para medidas de absorção de radiação por amostras no estado líquido, gasoso ou sólido, nas regiões, visível, ultravioleta e infravermelho do espectro eletromagnético. A absortividade molar $(\varepsilon)$ é uma grandeza característica da espécie absorvente, cuja magnitude depende do comprimento de onda da radiação incidente (ROCHA; TEIXEIRA, 2004).

\section{PARTE EXPERIMENTAL}

Utilizou-se nas pesagens balança analítica (BEL) e nas medidas de absorbância Espectrofotômetro (Thermo Scientific) ${ }^{\circ}$. Para a preparação das amostras sintéticas, utilizaram-se Óleo lubrificante mineral (Capella) e Óleo lubrificante sintético (Selenia), obtidos no comércio local. Para acidificar as amostras utilizou-se Ácido Clorídrico p.a. (Synth) ${ }^{\bullet}$, a extração dos óleos e graxas foi realizada com o solvente Clorofórmio p.a, (Synth) ${ }^{\circ}$ e o Sulfato de sódio anidro (Vetec) ${ }^{\oplus}$ foi utilizado para filtrar a fase aquosa extraída.

Como os óleos e graxas que estão presentes nos efluentes de oficinas mecânicas e postos de lavagens são provenientes de óleos lubrificantes compostos por óleos minerais e óleos sintéticos, foram utilizados estes dois óleos na realização dos experimentos. Primeiramente realizou-se uma varredura espectral de cada um dos tipos de óleos separadamente, em cubetas de quartzo, de 190 a $400 \mathrm{~nm}$ no espectrofotômetro, para encontrar a região de absorbância máxima e posteriormente a construção de uma curva analítica. Como o comprimento de onda que apresentou máximo de absorbância foi o mesmo para os dois óleos, optou-se por utilizar uma solução padrão com óleo mineral, que atualmente ainda é o mais utilizado nos óleos lubrificantes. Além disso, realizou-se uma varredura de comprimentos de ondas, na mesma faixa utilizada para os óleos, para o solvente clorofórmio, para verificar se o comprimento de onda de máxima absorbância seria próximo ao comprimento de onda do óleo, para evitar que ocorressem desvios da lei 
de Lambert-Beer.

A curva analítica foi preparada, pelo método de padrão externo em meio clorofórmio. Pesou-se 0,0303 g de óleo mineral em um balão volumétrico de $10 \mathrm{~mL}$ e avolumou-se com clorofórmio, preparando-se assim uma solução estoque de $3030,00 \mathrm{mg}$ $\mathrm{L}^{-1}$. Os padrões foram preparados, em triplicata, por diluição obtendo-se as respectivas concentrações: 60,60; 121,20; 242,40 e $303,00 \mathrm{mg} \mathrm{L}^{-1}$. Com o objetivo de verificar se a diluição dos padrões obedecia a lei de Lambert-Beer, realizou-se uma varredura de comprimentos de ondas com os padrões, para determinar qual seria o comprimento de onda de máxima absorbância para cada diluição. Após esta verificação, construiu-se a curva de calibração.

\subsection{Preparação da amostra sintética}

A próxima etapa foi a preparação de uma amostra sintética, a fim de verificar as figuras de mérito da metodologia. Para isso, preparou-se uma solução estoque de $5.510,00 \mathrm{mg} \mathrm{L}^{-1}$ de óleo em clorofórmio. Retirou-se uma alíquota de $1,00 \mathrm{~mL}$ da solução estoque para o funil de decantação contendo 500,00 $\mathrm{mL}$ de água deionizada com adição de ácido clorídrico para diminuir o valor do $\mathrm{pH}$ para próximo de 2, para a melhor solubilização da água com o óleo. A extração deu-se com adição de $25,00 \mathrm{~mL}$ de clorofórmio ao funil analítico. Agitou-se lentamente, aliviando a pressão e deixou-se descansar. Realizou-se o procedimento em triplicata. Após $10 \mathrm{~min}$, realizou-se a extração do óleo e clorofórmio que foram decantados no funil, filtrou-se o líquido extraído com sulfato de sódio anidro, para retirar qualquer gotícula de água que pudesse estar presente e então leu-se em espectrofo- tômetro no comprimento de onda de 242 $\mathrm{nm}$.

\subsection{Análise da amostra de efluente}

Para a análise da amostra real, proveniente de uma oficina mecânica, coletada por laboratório credenciado, mediu-se o volume de $630 \mathrm{~mL}$ da amostra em proveta e assim calculou-se o volume de clorofórmio necessário para a extração, $31,5 \mathrm{~mL}$, considerando um fator de diluição de 20. Após despejou-se a amostra para o funil de decantação, e adicionou-se $2,00 \mathrm{~mL}$ de ácido clorídrico. O volume de clorofórmio foi adicionado em parte no frasco de coleta da amostra e em parte na proveta utilizada para medir o volume, assim retirando qualquer resíduo de óleo que pudesse estar presente nas paredes, despejou-se o conteúdo no funil de decantação. Agitou-se o funil lentamente aliviando a pressão e deixou-se descansar por $10 \mathrm{~min}$. Fez-se o procedimento em triplicata.

Com a mesma amostra foi realizada análise pelo método gravimétrico, utilizado pelo laboratório credenciado, onde primeiramente verificou-se a acidificação da amostra e em seguida procedeu-se com a filtração à vácuo para reter os resíduos de óleo no papel filtro quantitativo. O papel filtro foi colocado em um cartucho de extração em estufa por $30 \mathrm{~min}$. Os copos extratores foram pesados antes da adição do papel filtro. $O$ cartucho foi adaptado em equipamento Soxlet, com $70 \mathrm{~mL}$ de hexano para a extração. Permaneceu em imersão por 1 hora e após mais 1 hora em lavagem, após recuperou-se o solvente. Levou-se os cartuchos para estufa for 2 horas e realizou-se a pesagem. 


\section{RESULTADOS E DISCUSSÃO}

Os valores de máxima absorbância das amostras de óleo mineral e de óleo sintético foram no mesmo comprimento de onda, conforme a Figura 2, permitindo que a curva fosse construída com apenas um dos óleos lubrificantes.

Figura 2: Espectros de varredura em comprimentos de onda de 190 a 400 nm para o óleo lubrificante mineral e óleo lubrificante sintético por espectrofotometria.

Figure 2: Scanning spectrum at wavelengths of 190 to $400 \mathrm{~nm}$ for mineral lubricating oil and synthetic lubricating oil by spectrophotometry.

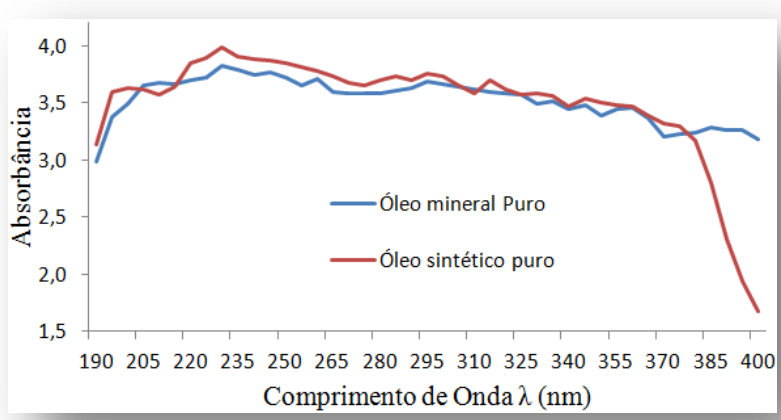

Fonte: Autores

Inicialmente testou-se também o solvente n-hexano, porém, apresentou desvio da lei de Lambert-Beer com a mistura em óleo. O solvente escolhido foi o clorofórmio, pois apresentou máximo de absorbância em 229 $\mathrm{nm}$. Conforme a Figura 3, ficando bem próximo do comprimento de máxima absorbância do óleo, evitando assim desvios da lei de Lambert-Beer.
Figura 3: Espectro de varredura em comprimentos de ondas de 190 a $240 \mathrm{~nm}$, para o solvente Clorofórmio por espectrofotometria.

Figure 3: Scanning spectrum in wavelengths from 190 to 240 $\mathrm{nm}$, for the solvent Chloroform by spectrophotometry.

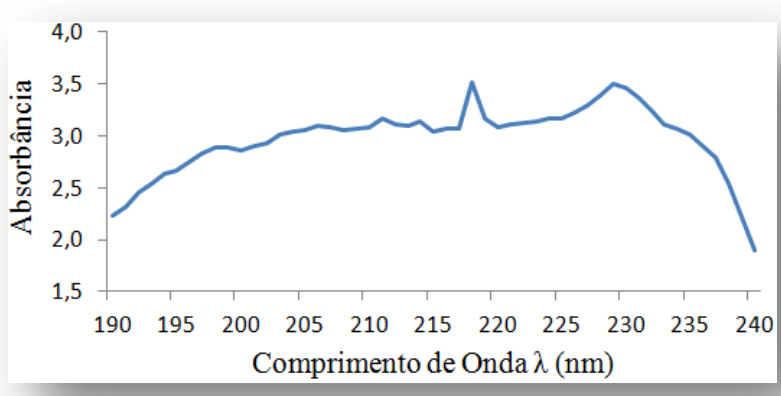

Fonte: Autores.

Para a escolha da faixa de concentrações nas quais a curva seria construída, levou-se em consideração os resultados que normalmente costumam-se encontrar nestes tipos de amostras, baseando-se no limite aceito pela Legislação que é de $10 \mathrm{mg} \mathrm{L}^{-1}$ (RIO GRANDE DO SUL, 2006).

A Figura 4 apresenta os espectros de varreduras, nos comprimentos de ondas de $190 \mathrm{~nm}$ a $400 \mathrm{~nm}$, das soluções padrões para a curva analítica para se verificar a região de máxima absorbância e sua concordância com a Lei de Lambert-Beer.

Figura 4: Espectro de varredura de comprimentos de ondas das soluções padrão com intervalo de $5 \mathrm{~nm}$ por espectrofotometria.

Figure 4: Wave length-scanning spectrum of standard solutions with $5 \mathrm{~nm}$ interval by spectrophotometry.

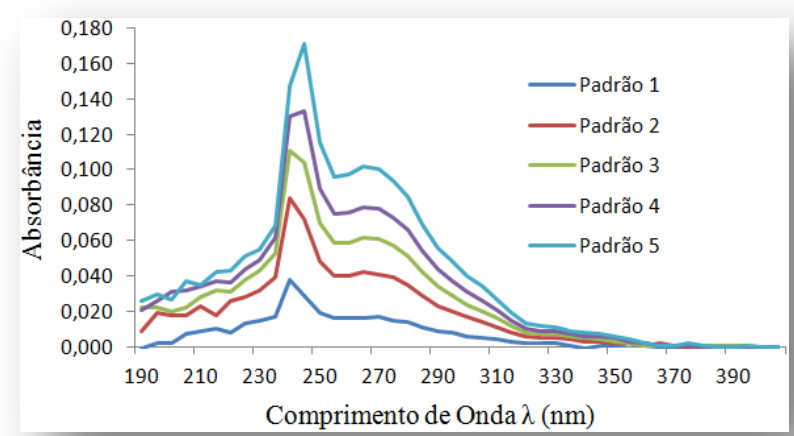

Fonte: Autores. 
A varredura foi realizada com um intervalo de $5 \mathrm{~nm}$, podendo-se verificar que os máximos de absorbância ficaram entre 240 $\mathrm{nm}$ e $245 \mathrm{~nm}$, comprovando seguir a lei de Lambert-Beer. Porém, para verificar com melhor exatidão o comprimento de onda onde havia máxima absorbância, realizou-se uma varredura com intervalo de $1 \mathrm{~nm}$, entre 240 a 245 nm, conforme Figura 5.

Figura 5: Espectro de varredura de comprimentos de ondas de 240 a $245 \mathrm{~nm}$ das soluções padrões com intervalo de $1 \mathrm{~nm}$.

Figure 5: Scanning spectrum of wavelengths from 240 to 245 $\mathrm{nm}$ of standard solutions with interval of $1 \mathrm{~nm}$.

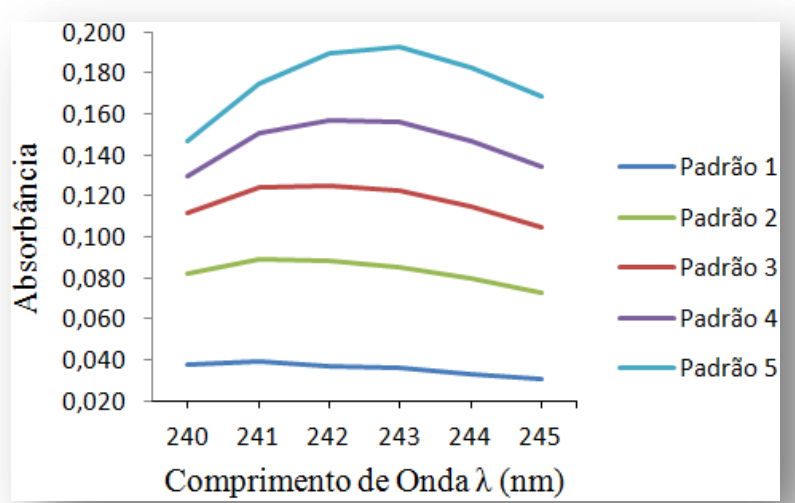

Fonte: Autores.

Realizou-se uma média dos comprimentos de ondas de máxima absorbância resultando em $242 \mathrm{~nm}$, sendo este utilizado para a leitura da curva analítica obtendo-se a equação da regressão $y=0,0007 x+0,0019$, com um coeficiente de correlação linear de 0,9985.

Para as amostras sintéticas, os valores de concentrações encontrados, já considerando o fator de diluição de 20, foram 12,53 \pm $0,13 \mathrm{mg} \mathrm{L}^{-1}$. A concentração da amostra sintética, realizada por gravimetria, apresentou $11,02 \mathrm{mg} \mathrm{L}^{-1}$. Sendo assim o erro relativo do processo foi de $13,70 \%$. O intervalo de recuperação, portanto, situou-se em $86,30 \%$. Valor compreendido ao valor acei- to entre $85-115 \%$ para a concentração analisada (SMEWW, 2012). Pode-se supor que o erro encontrado neste estudo foi devido a interferentes presentes na amostra sendo o método por espectrofotometria sensível a estes. Para a análise de óleos e graxas na amostra de efluente que também foi analisada por laboratório credenciado, obtevese os valores de concentração de 3,91 \pm 0,07 . Comparando-se com o resultado obtido por um Laboratório Credenciado, que foi de 4,35 $\mathrm{mg} \mathrm{L}^{-1}$, encontrou-se um erro relativo de $10,11 \%$. Sendo o intervalo de recuperação situado em 89,89 \%. Esse erro provavelmente pode ser explicado devido a extração realizada neste estudo onde podem ter ocorrido perdas de óleo que aderiu à superfície do funil de decantação.

\section{CONCLUSÃO}

O método de análise por espectrofotometria, proposto neste trabalho, mostrouse de forma positiva no sentido da diminuição de etapas de preparação de amostra, comparativamente ao método gravimétrico que utiliza a etapa da calcinação. Fato esse que proporciona a menor demanda de tempo de análise e menor volume de solvente envolvido. O método proposto apresenta uma perspectiva positiva para ser utilizado por laboratórios de prestação de serviços, desde que seja feita a sua otimização com parâmetros de mérito a fim de demonstrar, que de fato, é uma possibilidade segura dentro dos parâmetros de segurança exigidos pela legislação. Estudos futuros serão realizados para a otimização do método e um estudo de custos envolvidos em comparação ao método por gravimetria. 


\section{REFERÊNCIAS}

AZEVEDO J. B.; CARVALHO L. H. de; FONSECA V. M. Efeito da Degradação em Motor Automotivo nas Propriedades Termogravimétricas de Óleos Lubrificantes Minerais e Sintéticos. In: $3^{\circ}$ Congresso Brasileiro de P\&D em Petróleo e Gás. 2005, Salvador, Bahia. . Disponível em: <http://www.portala bpg.org.br/PDPetro/3/trabalhos/IBP0224_0 5.pdf>. Acesso em julho, 2017.

BRAGA, B. et al. Introdução a Engenharia Ambiental. 2. ed. São Paulo: Pearson Prentice Hall, 2005.

BRASIL. Resolução $N^{\circ} 430$, de 13 de maio de 2011. Dispõe sobre as condições e padrões de lançamento de efluentes, complementa e altera a Resolução no 357, de 17 de março de 2005, do Conselho Nacional do Meio Ambiente-CONAMA. Diário Oficial da União, $N^{\circ}$ 92, p. 89, de 16 de maio de 2011. BRASIL. Resolução n. ${ }^{\circ}$ 357, de 17 de março de 2005. Dispõe sobre a classificação dos corpos de água e diretrizes ambientais para o seu enquadramento, bem como estabelece as condições e padrões de lançamento de efluentes, e dá outras providências. Diário Oficial da União, no 053, p. 58, de 18 de março de 2005.

CIENFUEGOS, F. Análise Instrumental. Rio de Janeiro: Editora Interciência, 2000.

INSTITUTO ESTADUAL DO AMBIENTE (INEA). Oficinas Mecânicas e Lava Jatos - Orientações para o controle ambiental. Secretaria do Ambiente estado do Rio de Janeiro. 2. ed. 2014.

GUIMARÃES, A. K. V.; MELO, H. N. S.; MELO, J. J. S.; NETO, C. O. A.; Avaliação Estatística da Determinação do Teor de Óleos e Graxas em efluente doméstico. In: VI Simpósio Ítalo Brasileiro de Engenharia Sanitária e Ambiental, 6, 2002, Vitória. Apresentado em:
VI Simpósio Ítalo Brasileiro de Engenharia Sanitária e Ambiental, Vitória, 1-5 setembro de 2002.

METCALF \& EDDY. Inc. Wastewater Engineering. Treatment, Disposal and Reuse. McGraw-Hill. p. 1334. 1991.

NUVOLARI, A. Esgoto Sanitário - coleta, transporte, tratamento e reuso agrícola. 2. ed. São Paulo: Blucher, 2011.

ORSSATTO, F.; HERMES, E.; BOAS, M. A. V. Eficiência de Remoção de Óleos e Graxas de uma Estação de Tratamento de Esgoto Sanitário. Engenharia Ambiental. Espírito Santo do Pinhal, v. 7, n. 4, p. 249, outt/dez 2010. RIO GRANDE DO SUL. Resolução CONSEMA no 355/2017 de 13 de julho de 2017. Dispõe sobre os critérios e padrões de emissão de efluentes líquidos para as fontes geradoras que lancem seus efluentes em águas superficiais no Estado do Rio Grande do Sul. Diário Oficial do Estado, Porto Alegre, n. 136, p. 39.13 de julho de 2017.

ROCHA, F. R. P.; TEIXEIRA, L. S. G. Estratégias para aumento de sensibilidade em espectrofotometria Uv-Vis. Química Nova. v. 27, n. 5, p. 807, 2004.

SILVA, D. M. M.; REIS, F. A. G. V.; GIORDANO, L. do C.; MEDEIROS, G. A. Estudo de Caso de Empresa Distribuidora de Óleo Lubrificante: Adequação Segundo a Resolução CONAMA № 362/05. Engenharia Ambiental. Espírito Santo do Pinhal, v. 5, n. 3 , p. 286 , set/dez 2008.

SILVA, A. de P.; ALVES, M. C. C. Como Iniciar a Validação de Métodos Analíticos. ENQUALAB, Rede Metrológica do Estado de São Paulo, 2006.

SILVEIRA, E. L. C.; CALAND, L. B.; MOURA, C. V. R.; MOURA, E. M. Determinação de Contaminantes em Óleos Lubrificantes Usados e em Esgotos Contaminados por esses Lubrificantes. Química Nova. São Paulo. v. 29, n. 6, 
p. 1193, 2006.

STANDARD METHODS FOR THE EXAMINA-

TION OF WATER AND WASTEWATER, 22 nd Edition, 2014. Method 5520 D, American Public Health Association. American Water Works Association. Water Environment Federation. p. 5-42. 2014. Disponível em: <http://www.standardmethods.org/store/>. Acesso em julho de 2017.

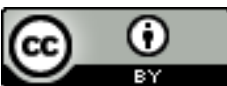
License information: This is an openaccess article distributed under the terms of the Creative Commons Attribution License, which permits unrestricted use, distribution, and reproduction in any medium, provided the original work is properly cited.

Artigo recebido em 15 de agosto de 2017.

Avaliado em 14 de setembro de 2017.

Aceito em 13 de outubro de 2017.

Publicado em 19 de dezembro de 2017.

\section{Como citar este artigo (ABNT):}

$\mathrm{KICH}$, Marina; BÖCKEL, Wolmir José. Análise de óleos e graxas em efluentes por espectrofotometria. Estação Científica (UNIFAP), Macapá, v. 7, n. 3, p. 61-69, set./dez. 2017. 